require large samples and it often takes as long as a week to complete the analysis. This simple micromethod (steatocrit) requires only $0.5 \mathrm{~g}$ of stool and the whole method takes about 30 minutes.

The steatocrit volumetrically relates the stool fat column to the stool solids column, which are of very different densities and are thus separated in the capillary centrifuge tubes. Although the relationship is imprecise (Fig. 2), it usefully distinguishes those babies with a steatocrit value greater than $25 \%, 91 \%$ of whom had stool fat contents greater than $0 \cdot 15$ gram/gram wet weight of stool, and might arbitrarily be considered to have a degree of fat malabsorption.

The steatocrit estimates stool fat concentration in small, sick infants on whom it is difficult to obtain large enough stool samples for such measurements by standard techniques. Moreover, for babies on formula milks or on banked human milk, the combination of the creamatocrit, the steatocrit, and 24-hour stool weight is a simple guide to daily fat absorption.

We thank Sister $\mathbf{P}$ Lucas, Sister $\mathbf{P}$ Townshend, and the nursing staff for their help with collection of the stools, and Alison Smith for her help with the statistical evaluation of the results.

\section{References \\ 1 Lucas A, Gibbs J A H, Lyster R L J, Baum J D. Creamato- crit: simple clinical technique for estimating fat concentra- tion and energy value of human milk. Br Med J 1978; i: 1018-20. \\ 2 Wybenga D R, James B M, Inkpen A. Lipids. In: Henry R J, Cannon D C, Winkelman J W, eds. Clinical chemistry: principles and techniques, second edition. Hagerstown: Harper \& Row, 1974: 1481-2.}

Correspondence to Dr J D Baum, Department of Paediatrics, John Radcliffe Hospital, Headington, Oxford OX3 9DU.

Received 27 January 1981

\title{
Effects of maternal smoking on fetal growth and nutrition
}

\author{
A $\mathbf{R}$ J BOSLEY, $\mathrm{J}$ R SIBERT, AND R G NEWCOMBE \\ Department of Child Health and Department of Medical Statistics, Welsh National School of Medicine, \\ Cardiff
}

SUMMARY Standard anthropometric measurements were made on 320 term neonates to investigate the influence of smoking on fetal growth and nutrition. Maternal height and triceps skinfold thickness were also measured. Of 320 infants, $126(39 \%)$ were born to mothers who smoked. Maternal triceps skinfold thickness was significantly smaller in smoking mothers. A correlation existed between maternal and infant triceps skinfold thickness. Measurements of infant growth, birthweight, occipito-frontal circumference, and crown-to-heel length were significantly smaller in infants of smoking mothers and remained significantly smaller when corrections were made for maternal triceps skinfold thickness, height, and social class. While these data do not exclude a nutritional mechanism for the effect of maternal smoking on the fetus, the major growth-retarding effects remain after corrections for this. This indicates that the mechanisms are multifactorial. The reduction in occipito-frontal circumference in infants of smoking mothers, and the possible significance of this is stressed.

The adverse effects of maternal smoking on fetal growth as judged by birthweight were first reported by Simpson in 1957. ${ }^{1}$ Numerous subsequent studies have confirmed this observation. Rush ${ }^{2}$ suggested that these adverse effects were mainly because of nutritional differences between mothers who smoked and mothers who did not, but other studies have produced evidence for a direct toxic effect on fetal growth. ${ }^{3}$

This study investigated the relationship between skinfold thickness (SFT) in mothers and anthropometric measurements in their babies related to smoking habits. We hoped this might determine whether a nutritional element exists to mediate the effects of maternal smoking on the fetus.

\section{Methods}

Three hundred and twenty term ( $>37$ weeks' gestation) infants and their mothers were studied. All infants were born in one unit in Cardiff (St David's Hospital) in 1978. Details of the pregnancy and measurements of mother and baby were made by one observer (ARJB), with informed parental consent. Gestation was assessed from menstrual dates and by the clinical method of Parkin et al. ${ }^{4}$

Infant length was measured on the neonatometer (Holtain Ltd). Infant occipito-frontal head circumference (OFC) was measured using a standard paper disposable tape measure. Infant subscapular and 
triceps SFT, and maternal triceps SFT were measured with Holtain skinfold calipers according to the method of Oakley et al. ${ }^{5}$ Measurements on the infant were made within 48 hours of birth and all suitable infants were measured on 2 days of each week. Social class was determined according to the occupation of the father, or if unmarried, the mother's father, using the Registrar General's classification.

\section{Results}

One hundred and twenty-six ( $39 \%)$ infants were born to mothers who had smoked at least 10 cigarettes a day throughout pregnancy. We found the differences between the mean values of birthweight, OFC, and length of infants of smoking and non-smoking mothers to be similar to those of other studies.

There was no significant difference in gestational age between smoking and non-smoking groups on either menstrual age or Parkin score (Table 1). The 6 infant birth measurements (birthweight, length, OFC, triceps SFT, subscapular SFT, and triceps plus subscapular SFT) were adjusted for gender by subtracting or adding half of the male or female difference according to whether the infant was a boy or girl.

The correlations between appropriate variables (the 6 listed, plus maternal height, triceps SFT, social class, and smoking) were then calculated. The 6 infant parameters were all strongly intercorrelated, all correlations being significant at the $P<0.001$ level. The effect of social class on each of the 6 infant outcome variables did not reach statistical significance on this sample.

Smoking had a highly significant effect $(\mathrm{P}<0.001)$ on birthweight, length, and OFC (Table 2), which remained after adjustment for maternal height and triceps SFT. Maternal smoking produced a significant reduction in infant triceps SFT at the $5 \%$ level; this remained after adjustment for maternal height, but failed to reach the $5 \%$ level of significance after adjustment for maternal triceps SFT.

A relationship was shown between maternal triceps SFT and maternal smoking habits, there being a significant reduction in smoking mothers $(\mathrm{P}<0.05)$.

Table 1 Mean gestational age in infants of smoking and non-smoking mothers (mean $\pm 1 S D$ )

\begin{tabular}{llll}
\hline & $\begin{array}{l}\text { Non-smoking } \\
\text { mothers }\end{array}$ & Smoking mothers & $t$ \\
\hline $\begin{array}{l}\text { Menstrual age } \\
\text { Parkin } \\
\text { assessment }\end{array}$ & $39.93 \pm 1.25$ & $40.01 \pm 1.28$ & $0.515 \mathrm{NS}$ \\
\hline
\end{tabular}

Table 2 Infant birth parameters, differences between infants of smoking and non-smoking mothers (mean $\pm 1 S D$ )

\begin{tabular}{lccc}
\hline & Birthweight $(\mathrm{kg})$ & $\begin{array}{l}\text { Crown-to-heel } \\
\text { length }(\mathrm{cm})\end{array}$ & $\begin{array}{l}\text { Occipito-frontal } \\
\text { circumference }(\mathrm{cm})\end{array}$ \\
\hline $\begin{array}{l}\text { Non smoking } \\
\text { mothers } \\
\text { (n=194) }\end{array}$ & $3.424 \pm 0.914$ & $49.96 \pm 1.80$ & $35.26 \pm 1.36$ \\
$\begin{array}{l}\text { Smoking } \\
\text { mothers } \\
(\mathrm{n}=126)\end{array}$ & $3.142 \pm 0.882$ & $48.81 \pm 1.95$ & $34.56 \pm 1.27$ \\
$\begin{array}{l}\text { Differences } \\
\mathrm{P}\end{array}$ & 0.282 & 1.15 & 0.70 \\
\hline & $<0.001$ & $<0.001$ & $<0.001$ \\
\hline
\end{tabular}

The effect of smoking on each of the 6 infant birth parameters was also adjusted for social class, maternal age, parity, and marital status, using an analysis of covariance. The level of significance remained unchanged.

\section{Discussion}

Maternal smoking during pregnancy is now known to be a cause of low birthweight. ${ }^{23}$ Other parameters of growth, for instance OFC and length, have also been shown to be adversely affected. ${ }^{6}$ This study confirms these findings and also shows a relationship between maternal and infant skinfold measurements.

Two mechanisms of fetal growth retardation of mothers who smoke have been proposed. Ac nutritional hypothesis has been postulated by Davies et al. ${ }^{6}$ who found a smaller weight gain in pregnancy in mothers who smoked than in mothers who did not. Nevertheless a study in Canada failed to demonstrate such an effect. ${ }^{7}$

An alternative explanation is that fetal growth is retarded by direct toxic effects of nicotine, cyanide, carbon monoxide, or other toxins.

Appreciable amounts of carboxyhaemoglobin have been found in the cord blood of infants of smoking mothers, which could adversely affect the fetal oxygenation and thus growth. ${ }^{3}$

Our data do not wholly support a nutritional hypothesis for the impaired fetal growth of infants of smoking mothers. The reduction in birthweight, length, and OFC in the smoking group remains highly significant after correction for maternal variables (height and triceps SFT). Therefore, the major growth-retarding effect of smoking can be observed after an adjustment for maternal nutritional status has been made. This suggests that the effect of maternal smoking on the fetus is mediated by mechanisms other than maternal nutrition alone.

Our data do not support the findings of Rush ${ }^{2}$ but we do not exclude an effect mediated by impaired maternal nutrition. Indeed, we found reduced maternal triceps SFT in smoking mothers. Therefore, 
smoking mothers are thinner and their babies are thinner too, but even accepting the limitations of correction for this effect, the growth-retarding effect of smoking on the fetus is hardly affected by this correction. A similar conclusion was derived from Cardiff Birth Survey data, in a community study on smoking and pregnancy. ${ }^{8}$ We postulate from our data and from other data already reported, that the growth-retarding effect of maternal smoking on the infant is a complex multifactorial one.

It is clear that efforts should be intensified to prevent expectant mothers smoking as there is evidence that there may be long-term effects on children's learning ability later in childhood, ${ }^{9}$ and we and Davies et al. ${ }^{6}$ have found a reduction in head circumference in the infants of smoking mothers.

We thank Dr E R Verrier Jones, Miss Joan Andrews, and $\mathrm{Mr} \mathrm{K}$ Johannsen, for allowing us to study their patients, and Miss $\mathbf{S}$ James for secretarial assistance.

\footnotetext{
References

1 Simpson W J. A preliminary report on cigarette smoking and the incidence of prematurity. Am J Obstet Gynecol 1957; 73: 808-15.

2 Rush D. Examination of the relationship between
}

birthweight, cigarette smoking during pregnancy, and maternal weight gain. J Obstet Gynaecol Br Commonw 1974; 81 : 746-52.

3 Cole P V, Hawkins L H, Roberts D. Smoking during pregnancy and its effects on the fetus. J Obstet Gynaecol Br Commonw 1972; 79: 782-7.

4 Parkin J M, Hey E N, Clowes J S. Rapid assessment of gestational age at birth. Arch Dis Child 1976; 51: 259-63.

5 Oakley J R, Parsons R J, Whitelaw A G L. Standards for skinfold thickness in British newborn infants. Arch Dis Child 1977; 52: 287-90.

6 Davies D P, Gray O P, Ellwood P C, Abernethy M. Cigarette smoking in pregnancy: associations with maternal weight gain and fetal growth. Lancet 1976; i: 385-7.

7 Meyer M B. How does maternal smoking affect birthweight and maternal weight gain? Am J Obstet Gynecol $1978 ; 131$ : 888-93.

8 Andrews J, McGarry J M. A community study of smoking in pregnancy. J Obstet Gynaecol Br Commonw 1972; 79: 1057-73.

9 Fogelman K. Smoking in pregnancy and subsequent development of the child. Child Care Health Dev 1980; 6: $233-49$.

Correspondence to $\operatorname{Dr}$ A R J Bosley, Department of Paediatrics, North Devon District Hospital, Raleigh Park, Barnstaple, North Devon EX31 4JB.

Received 12 March 1981

\title{
Bronchodilator effect of inhaled ipratropium bromide in wheezy toddlers
}

\author{
I G C HODGES, R C GROGGINS, A D MILNER, AND G M STOKES \\ Department of Child Health, Queen's Medical Centre, Nottingham
}

\begin{abstract}
SUMMARY Airways obstruction was measured before and after inhaled ipratropium bromide in 32 wheezy children aged between 3 months and 2 years 8 months using a total body plethysmograph and a modification of the forced oscillation technique. No relationship was found between age and incidence of response. About $40 \%$ of those under age 18 months had an improvement in lung function. This form of treatment may have a place in the management of the wheezy infant too young to respond to beta-2 stimulants.
\end{abstract}

Children under age 20 months who wheeze repeatedly still present a problem in management, as beta-2 adrenergic stimulant therapy is rarely effective. In an earlier study Lenney and Milner ${ }^{1}$ showed that salbutamol was an effective bronchodilator agent in wheezy children over age 20 months if administered via a nebuliser, but not in children under age 18 months. Other studies in children under age 12 months have failed to show any improvement in lung function after isoprenaline, ${ }^{2}$ salbutamol, ${ }^{3}$ phenylephrine, or adrenaline ${ }^{4}$ inhalation.

Ipratropium bromide, an anticholinergic drug, has been shown to be an effective bronchodilator agent in children over age 3 years when administered via a nebuliser. ${ }^{5}$ The degree of bronchodilatation was equal to that produced by nebulised salbutamol. The main effect of ipratropium bromide is thought to be in the large airways, mediated by blocking cholinergic receptors on bronchial smooth muscle. Its advantage over atropine by inhalation is that it has fewer side effects.

The aim of this study was to find out if wheezy children under age 3 years would respond to inhalation of ipratropium bromide and if so, would that response be age related. 